\title{
Kajian Pola Hidup Pasien Malaria yang Dirawat di Rumah Sakit Islam Unisma Tahun 2016-2017
}

\section{Study of Life Pattern of Malaria Patients Taken in Islamic Hospital of Unisma Year 2016-2017}

\author{
Herlinda Rahayu $^{1 *}$, Nour Athiroh ${ }^{2 * *}$, Hari Santoso ${ }^{3}$ \\ 1,2 Departemen Biologi, Fakultas Mipa, Universitas Islam Malang, Indonesia
}

\begin{abstract}
ABSTRAK
Malaria merupakan penyakit yang disebakan oleh Plasodium sp yang ditularkan melalui gigitan nyamuk Anopheles betina. Tujuan dari penelitian ini adalah untuk mengetahui persentase pasien malaria dan pola hidup pasien malaria yang dirawat di RSI UNISMA tahun 2016-2017. Penelitian ini dilakukan pada tanggal 28 juni 2018- 05 Agustus 2018 di 3 Kecamatan Lowokwaru, Klojen dan Kedung kandang. Metode penelitian ini adalah metode deskriptif yang bersifat observasional (non-eksperimental). Pengumpulan data menggunakan dua cara yaitu pengumpulan data primer dan data sekunder. Kuesioner diuji validitas dan reliabilitasnya. Hasil penelitian menunjukkan bahwa berdasarkan jenis kelamin penderita terbanyak adalah jenis kelamin laki-laki (56\%), Usia pasien pasca malaria lebih banyak terjadi pada usia produktif $15-25$ tahun $(62,5 \%)$ dan pada tingikat pendidikan banyak terjadi pada Sarjana (S1) dengan persentase $(87,5 \%)$ serta diagnosa utama paling banyak diagnosa Plasmodium vivax $(83,3 \%)$. Pola hidup pada 16 pasien malaria yang terkumpul dari 12 kusioner tersebut dan pola hidup yang tidak sehat yang mempengaruhi terjadinya penyakit malaria yaitu tidak memebersihkan kandang ternak setiap hari, tidak menutup tempat penampungan air dan tidak membersihkan sampah disekitar rumah.
\end{abstract}

Kata kunci : Malaria, Plasmodium vivax, deskriptif.

\section{ABSTRACT}

Malaria is a disease caused by Plasodium sp which is transmitted through the bite of a female Anopheles mosquito. The purpose of this study was to determine the percentage of malaria patients and the lifestyle of malaria patients treated at UNISMA RSI in 2016-2017. This research was conducted on June 28 201-0505 2018 in 3 Subdistricts of Lowokwaru, Klojen and Kedung Stables. This research method is a descriptive method that is observational (non-experimental). Data collection uses two methods: primary data collection and secondary data. The questionnaire was tested for validity and reliability. The results showed that based on the sex of the most sufferers were male sex $(56 \%)$, the age of post-malaria patients was more prevalent in the productive age of 15-25 years (62.5\%) and at the level of education a lot occurred in Bachelor (S1)) with a percentage (87.5\%) and the main diagnosis of most diagnoses of Plasmodium vivax (83.3\%). The pattern of life in 16 malaria patients collected from these 12 questionnaires is an unhealthy lifestyle that affects the occurrence of malaria, which is not cleaning the cattle shed every day, not closing water reservoirs and not cleaning garbage around the house.

Keywords: Malaria, Plasmodium vivax, descriptive.

\footnotetext{
*) Author's name with title, affiliation with some more details, department / division, address of letter, etc., Telp./handphone and e-mail: Username1@institution.xy

${ }^{* *}$ Second Author with title, affiliation with some more details, department / division, address, etc. Telp./handphone and E-mail: Username2@institution.xy
}

Diterima Tanggal 9 Agustus 2017 - Publikasi Tanggal 25 Agustus 2019 


\section{Pendahuluan}

Malaria merupakan satu di antara penyakit yang dikategorikan berbahaya di dunia penyakit yang disebabkan oleh Plasmodium sp yang ditularkan melalui gigitan nyamuk Anopheles betina [1]. Menurut data World Health Organization (WHO), estimasi insiden kasus malaria di dunia tahun 2010 mencapai 215 juta kasus dengan estimasi kematian sebesar 655 ribu jiwa[2].

Berdasarkan profil kesehatan Indonesia tahun 2016, Secara nasional angka kesakitan malaria selama tahun 2009-2016 di Indonesia cenderung menurun yaitu dari 1,8 per 1.000 penduduk berisiko pada tahun 2009 menjadi 0,84 per 1.000 penduduk berisiko pada tahun 2016 [3] Kota Malang merupakan kota bukan endemis malaria, selama tahun 2014 tidak ada kasus malaria di Kota Malang termasuk malaria import[4].

Rumah Sakit merupakan salah satu instansi pemerintah di bidang kesehatan masyarakat. Salah satu rumah sakit yang menjadi rujukan penyakit Malaria adalah Rumah Sakit Islam (RSI) UNISMA Malang. Hasil Praktek Kerja Lapang (PKL) saya pada bulan Desember tahun 2017-Januari tahun 2018 selama 1 bulan terdapat 2 pasien malaria[5].

Dari data tersebut, maka perlu dilakukan database kajian pola hidup pasien malaria di Rumah Sakit Islam (RSI) UNISMA tahun 2016-2017 berdasarkan jenis kelamin, usia, tingkat pendidikan, diagnosa utama, sering keluar rumah pada malam hari, lingkungan yang bersih atau kotor sehingga berkontribusi pada instansi kesehatan dan masyarakat.

\section{Material dan Metode}

Alat yang digunakan dalam penelitian ini adalah kamera dan perlengkapan menulis dan untuk mendapatkan data dari masyarakat bahan yang digunakan dalam penelitian ini adalah data primer (data hasil identifikasi) dan data sekunder yaitu data rekam medik kasus Malaria pada tahun 20162017 di Rumah Sakit Islam ( RSI) UNISMA Malang. Metode yang digunakan adalah deskriptif.Desain penelitian yang akan digunakan dalam penelitian ini adalah Observasional (noneksperimental) secara deskriptif.

Dalam penelitian ini diteliti secara langsung kajian penderita malaria yang dirawat di Rumah Sakit Islam (RSI) UNISMA Malang tahun 2016-2017 dengan menggunakan alat pengumpulan data berupa kuesioner dan foto. Data-data yang diidentifikasi berupa faktor data jenis kelamin, usia, tingkat pendidikan, pekerjaan dan diagnosa utama penyakit malaria,sering keluar rumah pada malam hari, lingkungan bersih atau kotor, penggunaan bubuk abate (Larvasida) dan lain-lain.

Penelitian yang diamati secara langsung ialah mengenai jenis kelamin, usia, diagnosa utama penyakit malaria, pekerjaan keluar rumah pada malam hari, lingkungan bersih atau kotor, penggunaan bubuk abate (Larvasida) dan lain-lain.

Populasi dalam penelitian ini ialah masyarakat yang berada di wilayah 7 Kelurahan yaitu Lowokwaru, Merjosari, Togomas, Mojolangu, Klojen, Penanggungan, Cemoro kandang dan 3 Kecamatan yaitu Lowokwaru, Klojen, dan Kedungkandang dan sampel yang menjadi dasar penelitian adalah paien malaria yang dirawat di RSI UNISMA tahun 2016-2017 yang berjumlah16 orang.

Teknik pengumpulan data menggunakan data primer dan data sekunder. Data primer diperoleh dari hasil sumber informasi langsung yang berasal dari kusioner dan wawancara pasien pasca malaria sesuai data yang sudah diperoleh dari data rekam medik, data sekunder diperoleh dari data rekam medik kasus Malaria selama tahun 2016-2017 di Rumah Sakit Islam (RSI) UNISMA Malang.

Kuesioner diuji validitas dan reliabilitasnya kemudian dilakukan deskripsi dan scoring sehingga dapat diperoleh persentase tiap kuesioner dan mengetahui kategori berupa baik atau buruk. Hasil dari persentase penelitian untuk variabel diinterpretasikan dengan melakukan analisa univariat menggunakan bantuan program SPSS 15. 


\section{Hasil dan Diskusi}

Faktor Resiko Malaria berdasarkan Jenis Kelamin, Usia, Tingkat Pendidikan dan Diagnosa Utama Pasien Pasca Malaria tahun 2016-2017: Berdasarkan gambar 1 dari data hasil kusiner pada pasien malaria di Rumah Sakit Islam (RSI) UNISMA Malang tahun 2016-2017 di 3 Kecamatan (Lowokwaru, Klojen, dan Kedungkandang) dan 7 (Lowokwaru, Merjosari, Togomas, Mojolangu, Klojen, Penanggungan, Cemoro kandang) diketahui bahwa pada parameter jenis kelamin Laki-laki berjumlah 9 pasien dengan persentase $56 \%$ dan jenis kelamin perempuan berjumlah 7 pasien dengan persentase $44 \%$ dari total keseluruhan 16 pasien, dari hasil data kuesioner tersebut pasien laki-laki lebih besar nilai persentasenya yaitu 56\% karena laki-laki sangat rentan terjangkit penyakit malaria disebabkan sering beraktifitas di luar rumah dari pada perempuan terutama pada malam hari.

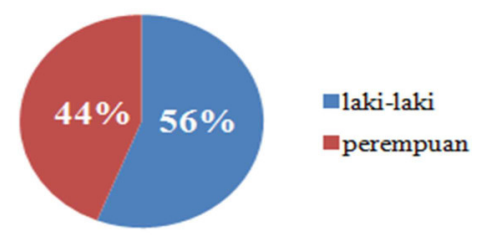

Gambar 1. Diagram Responden Berdasarkan Jenis Kelamin Pasien Malaria pada tahun 2016-2017

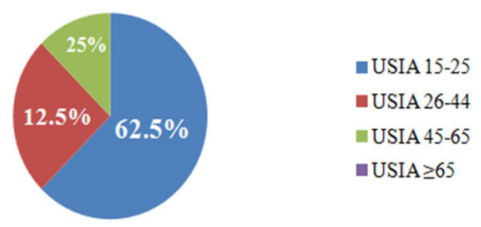

Gambar 2. Diagram Responden Berdasarkan Usia Pasien Malaria pada tahun 2016-2017

Berdasarkan gambar 2 dari data hasil kusiner pada pasien malaria di Rumah Sakit Islam (RSI) UNISMA Malang tahun 2016-2017diketahui pada parameter usia, kasus malaria pertama pada pada usia 15-25 tahun, jumlah total 10 responden $(6,25 \%)$, kedua usia 26-44 tahun, jumlah total 4 responden (25\%), ketiga usia 45-65 tahun, jumlah total 2 responden (12,5\%), ke empat, ke lima $\geq 65$ tahun, tidak ada responden dalam identifikasi pasien pasca malaria $(0 \%)$, pada penelitian dari keempat macam usia, usia yang paling banyak terjangkit penyakit Malaria adalah usia produktif yaitu yang pertama usia 15-25 tahun sebanyak 10 responden $(6,25 \%) \%)$ karena rata-rata usia produktif adalah pelajar/Mahasiswa yang cendrung kurang menjaga kesehatan diri sendiri dan lingkungannya seperti kebiasaan keluar malam tanpa menghiraukan tempat yang dituju bagaimana kebersihan lingkungannya, sering bergadang dan nongkrong dengan sesama temannya sehingga lupa mengatur waktu dan kesehatannya dan menyebabkan imunitasnya rendah sehingga mudah terinfeksi malaria.

Berdasarkan Gambar 3 bahwa pasien pasca malaria di Rumah Sakit Islam (RSI) UNISMA Malang tahun 2016-2017 diketahui bahwa pada parameter tingkat pedidikan dengan jumlah kasus Malaria yang terdapat empat kelompok pendidikan. Kelompok pertama pendidikan jenjang SMA dimana tidak ada responden pada jenjang SMA (0\%), kedua pendidkan tingkat Sarjana (S1) dengan jumlah total 14 responden (87,5\%), ketiga tingkat pendidikan jenjang Master (S2) dengan jumlah total 1 responden (6,25\%), keempat tingkat pendidikan Doktor (S3) dengan jumlah 1 responden $(6,25 \%)$. Berdasarkan hasil penelitian Rustan tahun 2002 bahwa tingkat pendidikan sangat berhubungan dengan pemahaman dan baca tulis seseorang, sehingga seseorang yang memeiliki kemampuan 


\section{e-Jurnal Ilmiah BIOSAINTROPIS (BIOSCIENCE-TROPIC) Volume 5/ No.: 1 / Halaman 31 - 37 / Agustus Tahun 2019 ISSN : 2460-9455 (e) - 2338-2805(p)}

pemahaman dan baca tulis yang tinggi akan mempengaruhi pada pemahaman konsep sehat dan sakit sehinnga memepengaruhi perilaku individu atau keluarga untuk hidup sehat termasuk didalam upaya individu dan keluarga dalam mencengah penyakit malaria.

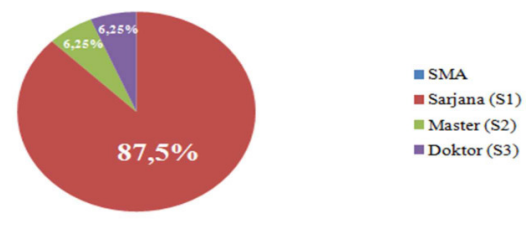

Gambar 3. Diagram Responden Berdasarkan Tingkat Pendidikan Pasien Malaria pada tahun 20162017

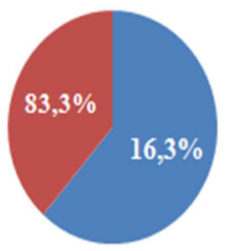

- Plasmodium vivak

- Plasmodium falcifarum

Gambar 4. Diagram Responden Berdasarkan Diagnosa Utama Pasien Malaria pada tahun 2016-2017

Berdasarkan gambar 4 diketahui bahwa pada parameter diagnose terdapat 2 macam diagnosa utama pada pasien pasca malaria, Pertama diagnosa utama Plasmodium vivax dengan jumlah total 10 responden (83,3\%), kedua Plasmodium falcifarum jumlah total 6 responden (16,3\%), jadi dari kedua macam diagnosa utama diketahui yang paling banyak adalah diagnosa utama Plasmodium vivax Kebanyakan pasien adalah mahasiswa dan setelah ditelusuri lewat wawancara dari 16 responden pasien malaria adalah malaria yang dialami adalah malaria bawaan dari daerahnya sendiri, yang kebanyakan dari indonesia bagian timur (Papua dan NTB) sehingga ketika mereka lupa menjalani pola hidup tidak sehat maka penyakit malaria tersebut kambuh lagi.

Pola Hidup Pasien Malaria Di Rumah Sakit Islam (RSI) UNISMA Tahun 2016-2017: Berdasarkan pola hidup pasien malaria di RSI UNISMA yaitu membersihkan kandang hewan ternak setiap hari, menutup tempat penampungan sampah, kambuh kembali, minum obat teratur/tidak teratur dan keluar malam yang sangat berhubungan dengan malaria dijelaskan dalam bentuk korelasi yaitu sebagai berikut:

Berdasarkan diagnosa utama, dari hasil uji korelasi menunjukkan bahwa pertanyaan nomor 10 yaitu membersihkan kandang hewan ternak setiap hari mempunyai hubungan signifikan dengan diagnosa utama (Plasmodium falcifarum/ Plasmodium vivax), dengan koefisien korelasi sebesar 0.501 dan nilai signifikansi sebesar $0.044(\mathrm{p}<0.05)$. Kebersihan kandang yang tidak baik dapat menjadikan kandang sebagai tempat yang strategis untuk beristirahat dan berkembangbiak nyamuk terutama nyamuk Anopheles. Dengan jarak terbang (flight range) antara 0,5-3 km dari tempat perkembangbiakannya sangat memungkinkan untuk nyamuk berkontak dengan manusia di dalam rumah.

Berdasarkan hasil korelasi menunjukkan bahwa pertanyaan nomor 5 yaitu menutup tempat penampungan air dimana mempunyai hubungan signifikan dengan kambuhnya penyakit malaria, dengan koefisien korelasi sebesar -0.667 dan nilai signifikansi sebesar $0.008(p<0.05)$. Lingkungan bersih dan kotor sangat berhubungan terhadap berbagai sumber terjadinya berbagai penyakit terutama 
penyakit malaria yang disebabkan oleh nyamuk Anopheles betina yang sangat menyukai hinggap dan hidup ditempat yang lembab seperti digenangan-genangan air dan rawa-rawa.

Berdasarkan hasil uji korelasi menunjukkan bahwa pertanyaan nomor 12 yaitu Selalu membersihkan sampah disekitar rumah. mempunyai hubungan signifikan dengan kambuhnya penyakit malaria, dengan koefisien korelasi sebesar -0.496 dan nilai signifikansi sebesar 0.040 $(\mathrm{p}<0.05)$.

Tabel 2. Deskripsi Jawaban Responden

\begin{tabular}{|c|c|c|c|c|c|c|c|c|c|}
\hline \multirow{3}{*}{ No } & \multirow{3}{*}{ Aspek } & \multicolumn{8}{|c|}{ Jumlah Jawaban Responden } \\
\hline & & \multicolumn{2}{|c|}{ Selalu } & \multicolumn{2}{|c|}{ Sering } & \multicolumn{2}{|c|}{$\begin{array}{c}\text { Kadang- } \\
\text { kadang }\end{array}$} & \multicolumn{2}{|c|}{$\begin{array}{l}\text { Tidak } \\
\text { Pernah }\end{array}$} \\
\hline & & $\Sigma$ & $\%$ & $\sum$ & $\%$ & $\sum$ & $\%$ & $\sum$ & $\%$ \\
\hline 1 & $\begin{array}{l}\text { Keluar Rumah pada } \\
\text { malam hari. }\end{array}$ & 3 & $18,7 \%$ & 4 & $25 \%$ & 8 & $50 \%$ & 1 & $6,25 \%$ \\
\hline 2 & $\begin{array}{c}\text { Selalu mengikuti } \\
\text { penyuluhan malaria. }\end{array}$ & 5 & $31,2 \%$ & 3 & $18,7 \%$ & 5 & $31,2 \%$ & 3 & $18,7 \%$ \\
\hline 3 & $\begin{array}{l}\text { Menggunakan kelambu } \\
\text { dan kawat kasa pada } \\
\text { vertilasi rumah }\end{array}$ & 2 & $12,5 \%$ & 7 & 43,7 & 6 & $37,3 \%$ & 1 & $6,25 \%$ \\
\hline 4 & $\begin{array}{c}\text { Memakai obat anti } \\
\text { nyamuk dan hand body } \\
\text { lotion. }\end{array}$ & 2 & $12,5 \%$ & 6 & $37,5 \%$ & 6 & $37,3 \%$ & 2 & $12,5 \%$ \\
\hline 5 & $\begin{array}{l}\text { Menutup tempat } \\
\text { penampungan air }\end{array}$ & 5 & $31,2 \%$ & 10 & $62,5 \%$ & 1 & $6,25 \%$ & 0 & $0 \%$ \\
\hline 6 & $\begin{array}{l}\text { Menguras Bak mandi } 1 \\
\text { minggu sekali. }\end{array}$ & 7 & $43,7 \%$ & 7 & $43,7 \%$ & 1 & $6,25 \%$ & 1 & $6,25 \%$ \\
\hline 7 & $\begin{array}{c}\text { Memberikan bubuk abate } \\
\text { pada tempat } \\
\text { penampungan air. }\end{array}$ & 1 & $6,25 \%$ & 5 & $31,2 \%$ & 10 & $62,5 \%$ & 0 & $0 \%$ \\
\hline 8 & $\begin{array}{c}\text { Membersihkan } \\
\text { lingkungan sekitar rumah }\end{array}$ & 6 & $37,5 \%$ & 6 & $37,5 \%$ & 3 & $18,7 \%$ & 1 & $6,25 \%$ \\
\hline 9 & $\begin{array}{l}\text { Membersihkan tumbuhan } \\
\text { air }\end{array}$ & 5 & $31,2 \%$ & 5 & $31,2 \%$ & 5 & $31,2 \%$ & 1 & $6,25 \%$ \\
\hline 10 & $\begin{array}{l}\text { Membersihkan Kandang } \\
\text { hewan ternak setiap hari. }\end{array}$ & 10 & $62,5 \%$ & 4 & $25 \%$ & 2 & $12,5 \%$ & 0 & $0 \%$ \\
\hline 11 & $\begin{array}{l}\text { Menimbun sampah } \\
\text { kaleng. }\end{array}$ & 2 & $25 \%$ & 8 & $50 \%$ & 5 & $31,2 \%$ & 1 & $6,25 \%$ \\
\hline 12 & $\begin{array}{c}\text { Membersihkan } \\
\text { pohonrimbun disekitar } \\
\text { rumah }\end{array}$ & 7 & $43,7 \%$ & 3 & $18,7 \%$ & 6 & $37,5 \%$ & 0 & $0 \%$ \\
\hline
\end{tabular}




\section{Kesimpulan}

Jenis kelamin penderita malaria terbanyak adalah jenis kelamin laki-laki (56\%), Usia pasien pasca malaria lebih banyak terjadi pada usia produktif $15-25$ tahun $(62,5 \%)$ dan pada tingkat pendidikan banyak terjadi pada Sarjana (S1) $(87,5 \%)$ serta diagnosa utama paling banyak diagnosa Plasmodium vivax $(83,3 \%)$. Pola hidup yang tidak sehat yaitu tidak membersihkan kandang hewan ternak setiap hari, tidak menutup tempat penampungan air dan tidak memebersihkan lingkungan sekitar, membuang sampah berhubungan dengan kambuhnya penyakit malaria.

Bagi Rumah Sakit Islam (RSI) UNISMA Malang untuk menambah program kesehatan khususnya pada malaria dengan memeberikan penyuluhan dan bimbingan kepada pasien malaria. Bagi Masyarakat terutama masyarakat yang endemisitas malaria tinggi untuk lebih memeperhatikan perilaku dan cara hidup yang sehat. Bagi peneliti diharapkan dapat mengembangkan dan meneliti lebih lanjut tentang variabel yang berbeda upaya-upaya yang harus dialakukan agar terhindar dari penyakit malaria.

\section{Daftar Pustaka}

[1] Budiarto . 2001. Biostatistik untuk Kedokteran dan Kesehatan Masyarakat. EGC. Jakarta.

[2] Departemen kesehatan Republik Indonesia. 2010. Pedoman Tatalaksana Kasus Malaria di Indonesia. Depkes RI. Jakarta.

[3] Departemen Kesehatan Jawa Timur, 2011. Profil Kesehatan Jawa Timur. Depkes Jawa Timur. Jakarta.

[4] Dinas Kesehatan Kota Malang. 2014. Profil Kesehatan kota Malang Tahun 2014. Dipkes Kota Malang. Malang.

[5] Rahayu. 2018. Laporan Praktek Kerja Lapang Pemeriksaan Darah di Rumah Sakit Islam (RSI) Malang. UNISMA. Malang.

[6] Murti. 2012. Desain Studi. FK-Universitas Sebelas Maret. Surakarta. 